\title{
Attenuation of taste-aversion conditioning in rats recovered from thiamine deficiency: Atropine vs. lithium toxicosis
}

\author{
S. P. SPARENBORG, W. F. BUSKIST, H. L. MILlER, JR., D. E. FLEMING, \\ and P. C. DUNCAN \\ Brigham Young University, Provo, Utah 84602
}

\begin{abstract}
Four groups of rats (the recovery groups) were fed on a synthetic thiamine-deficent diet while two other groups (the supplemented groups) were fed on the same diet but received thiamine in their water so as not to become deficient. Following a 5-day recovery period during which all rats were given a choice between the deficient diet and a chocolate-flavored thiamineenriched diet that preceded a single exposure to the chocolate-enriched diet only, two recovery groups received injections of one of two concentrations of lithium chloride (.3 M or .5 M), the two other recovery groups received injections of one of two levels of methyl atropine $(1.0 \mathrm{mg} / \mathrm{kg}$ or $3.0 \mathrm{mg} / \mathrm{kg})$, one supplemented group received injections of lithium chloride (.3 M only), and the other supplemented group received injections of methyl atropine $(1.0 \mathrm{mg} / \mathrm{kg}$ only). Rats avoided the chocolate-enriched diet paired with toxicosis, except when that food had been previously paired with recovery from vitamin deficiency. These results confirm earlier studies that reported attenuation of taste aversions in rats recovered from thiamine deficiency and extend the generality of this "attenuation effect" to include resistance to taste-aversion otherwise readily induced by a different toxic agent: methyl atropine.
\end{abstract}

Detailed investigations of the conditioned flavoraversion paradigm, in which a flavor is paired with noxious events such as toxicosis, have resulted in the classification of three general categories of food: familiaraversive, or foods paired with unpleasant consequences; familiar-safe, or foods paired with innocuous consequences; and novel, or foods that have never been sampled (see Zahorik, 1977, for a review). Several other researchers have recently gathered evidence that supports the existence of a fourth category of foods: familiar-positive, or foods that have been paired with the beneficial effects of ingestion, such as recovery from illness (Buskist, Miller, Duncan, \& Fleming, 1980; Buskist, Miller, Fleming, \& Sparenborg, 1981; Zahorik, 1977; Zahorik \& Bean, 1975). Familiar-positive foods are distinguished from all other foods in two ways: They are typically highly preferred foods and are highly resistant to subsequent associations with toxicosis.

It is this latter aspect of familiar-positive foods that figured in the present research. It is well documented that flavor aversions may be induced by a wide variety of pharmacological agents that differ in terms of effect (e.g., both morphine and morphine antagonists such as naloxone may be used to induce aversions; LeBlanc \& Cappell, 1974); for a review, see Gamzu (1977). Without exception, those who have examined the attenuation effect, that is, the mitigation of flavor aversion in animals recovered from illness (i.e., vitamin deficiency)

Research reported herein was supported by a Sigma Chi Grant-In-Aid-of-Research and an ASBYU grant to the second author. have employed lithium choloride $(\mathrm{LiCl})$ as the pharmacological agent in the attempt to induce aversion. Thus the generality of this attenuation effect may be considered suspect until it can be demonstrated that flavors paired with the noxious effects of other agents are also resistant to aversive conditioning.

The present investigation sought to extend the generality of the attenuation effect by employing a different toxic agent-methyl atropine (MA), a peripherally acting anticholinergic compound that has previously been shown to induce flavor aversions in rats (Vogel \& Clody, 1972). Rats were allowed to recover from thiamine deficiency by ingesting a specially flavored, thiamine-enriched diet prior to injections of either $\mathrm{LiCl}$ or MA.

\section{METHOD}

Thirty male albino rats were placed in individual wire-mesh cages $(24 \times 20 \times 19 \mathrm{~cm})$ at 21 days of age. The animals were housed inside a temperature-controlled room $\left(22^{\circ} \mathrm{C}\right)$ with a 12-h light-dark cycle. Securely positioned at the front corners of each cage were 2-oz food cups. Water was available continually and food was available for $23 \mathrm{~h}$ each day throughout all conditions of the experiment. The 1-h food-deprivation interval occurred at the same time daily and was utilized to weigh and replenish food cups for each animal.

A synthetic thiamine-deficient diet was placed in both food cups for the first 21 days of the experiment. The thiaminedeficient diet consisted of casein (20\%), corn oil (4\%), salt mix XIV (5\%), B-vitamin mix minus $\mathrm{B}_{1}(2 \%)$, vitamins A, D, and E in corn oil $(1 \%)$, choline bitartrate $(1 \%)$, and sucrose $(67 \%)$. Ten rats received a supplement of thiamine hydrochloride in their drinking water $\left(10 \mathrm{mg} \mathrm{B} / \mathrm{HCl} /\right.$ liter $\left.\mathrm{H}_{2} \mathrm{O}\right)$ to prevent thiamine deficiency. The remaining 20 rats experienced thiamine deprivation. For the next 5 days (Days 22-26), all rats were 
offered both the familiar deficient diet and a new chocolateflavored, thiamine-enriched (CE) diet. The CE diet consisted of the thiamine-deficient diet with the addition of thiamine hydrochloride $(10 \mathrm{mg} / \mathrm{kg}$ diet $)$ and chocolate fudge pudding $\mathrm{mix}$ $(170 \mathrm{~g} / 3,250 \mathrm{~g}$ diet $)$. This 5-day sequence constituted the recovery period. Day 27 (CE only), all rats were offered the $\mathrm{CE}$ diet eaten during the recovery period. Animals were then divided into subgroups and matched according to the percentage of $\mathrm{CE}$ diet eaten during the recovery period. (This provided the assurance that each subgroup within each treatment consumed an approximately equal amount of CE diet. Therefore, differences in CE diet consumption during the subsequent test period would not be attributable to differences in initial preference for the $\mathrm{CE}$ diet.)

At the beginning of Day 28, one of the two supplemented groups, designated $\mathrm{S} / \mathrm{P}, 1.0 \mathrm{mg} / \mathrm{kg} \mathrm{MA}$, and one of the four deficiency groups, designated $\mathrm{D} / \mathrm{P}, 1.0 \mathrm{mg} / \mathrm{kg} \mathrm{MA}$, received intraperitoneal (ip) injections of atropine methyl nitrate (Sigma Chemical Company) in physiological saline $(.5 \mathrm{mg} / \mathrm{ml})$ at a dose of $1 \mathrm{mg} / \mathrm{kg}$ body weight. A second deficiency group $(D / P$, $3.0 \mathrm{mg} / \mathrm{kg} \mathrm{MA}$ ) received injections of atropine methyl nitrate in physiological saline $(1.5 \mathrm{mg} / \mathrm{ml})$ at a dose of $3 \mathrm{mg} / \mathrm{kg}$. The remaining supplemented group $(\mathrm{S} / \mathrm{P}, .3 \mathrm{M} \mathrm{LiCl})$ and third deficient group $(\mathrm{D} / \mathrm{P}, .3 \mathrm{M} \mathrm{LiCl})$ received ip injections of $.3 \mathrm{M} \mathrm{LiCl}$ (ip, per liter of physiological saline at $1 \%$ body weight), and the fourth deficient group $(\mathrm{D} / \mathrm{P}, .5 \mathrm{M} \mathrm{LiCl})$ received injections of $.5 \mathrm{M} \mathrm{LiCl}$, also at $1 \%$ body weight. All rats were subsequently offered both the familiar deficient diet and the chocolateflavored enriched diet for the next 4 days (Days 28-31).

\section{RESULTS AND DISCUSSION}

During the 5-day recovery period, rats in the supplemented group consumed $69 \%$ of their dietary intake from the $\mathrm{CE}$ source; rats in the deficient group consumed significantly more (92\%) from the same source $[t(28)=4.98, p<.01]$. On Day 27 (CE only), however, there was no significant difference in the group's total CE intake $[t(28)=1.94]$.
Figure 1 depicts the amount of $\mathrm{CE}$ diet consumed as a percentage of total intake over the entire postpoisoning period (Days 28-31). Numbers in brackets represent the mean percentage of $C E$ diet consumed during the recovery period. During the initial $24-\mathrm{h}$ period following injection, Groups $\mathrm{S} / \mathrm{P}, 1.0 \mathrm{mg} / \mathrm{kg} \mathrm{MA}$ and $\mathrm{S} / \mathrm{P}, .3 \mathrm{M} \mathrm{LiCl}$ consumed significantly less $\mathrm{CE}$ diet than did their counterparts in the four deficient groups $[F(5,24)=$ $12.83, \mathrm{p}<.01]$. The Scheffe test revealed the following differences; S/P, $1.0 \mathrm{mg} / \mathrm{kg}$ MA vs. $\mathrm{D} / \mathrm{P}, 1.0 \mathrm{mg} / \mathrm{kg}$ MA, $F_{\mathrm{s}}=21.10(\mathrm{p}<.01) ; \mathrm{S} / \mathrm{P}, 1.0 \mathrm{mg} / \mathrm{kg}$ MA vs. $\mathrm{D} / \mathrm{P}$, $3.0 \mathrm{mg} / \mathrm{kg} \mathrm{MA}, \mathrm{F}_{\mathrm{s}}=22.06(\mathrm{p}<.01) ; \mathrm{S} / \mathrm{P}, .3 \mathrm{M} \mathrm{LiCl}$ vs. $\mathrm{D} / \mathrm{P}, .3 \mathrm{M} \mathrm{LiCl}, \mathrm{F}_{\mathrm{s}}=26.56(\mathrm{p}<.01) ; \mathrm{S} / \mathrm{P}, .3 \mathrm{M} \mathrm{LiCl}$ vs. $\mathrm{D} / \mathrm{P}, .5 \mathrm{M} \mathrm{LiCl}, \mathrm{F}_{\mathrm{s}}=24.66(\mathrm{p}<.01)$. No reliable differences were found between the two $\mathrm{S} / \mathrm{P}$ groups $\left(F_{s}=.83\right)$ or between any of the $D / P$ groups $\left(F_{s}=\right.$ $.010-.419)$.

These effects were further confirmed by a series of correlated $t$ tests conducted on the differences in CE intake during the recovery period (Days 22-26) and the initial 24-h postpoisoning period (Day 28) for each group. Only the supplemented subgroups showed reliable differences $[\mathrm{S} / \mathrm{P}, 1.0 \mathrm{mg} / \mathrm{kg} \mathrm{MA}, \mathrm{t}(4)=2.90$, and $\mathrm{S} / \mathrm{P}, .3 \mathrm{M} \mathrm{LiCl}, \mathrm{t}(4)=3.01$; both groups, $\mathrm{p}<.05$ ] Figure 1 also shows that each group remained fairly consistent in terms of the percentage of CE diet ingested throughout the entire 4-day postpoisoning period.

During the recovery period (Days 22-26), deficient rats, in contrast to supplemented rats, showed a strong preference for the CE diet. This finding confirms earlier work that found a strong "novelty response" in deficient but not healthy rats (cf. Rodgers \& Rozin, 1966). The present research also confirms the earlier work of Buskist et al. (1980), Buskist et al. (1981), and Zahorik

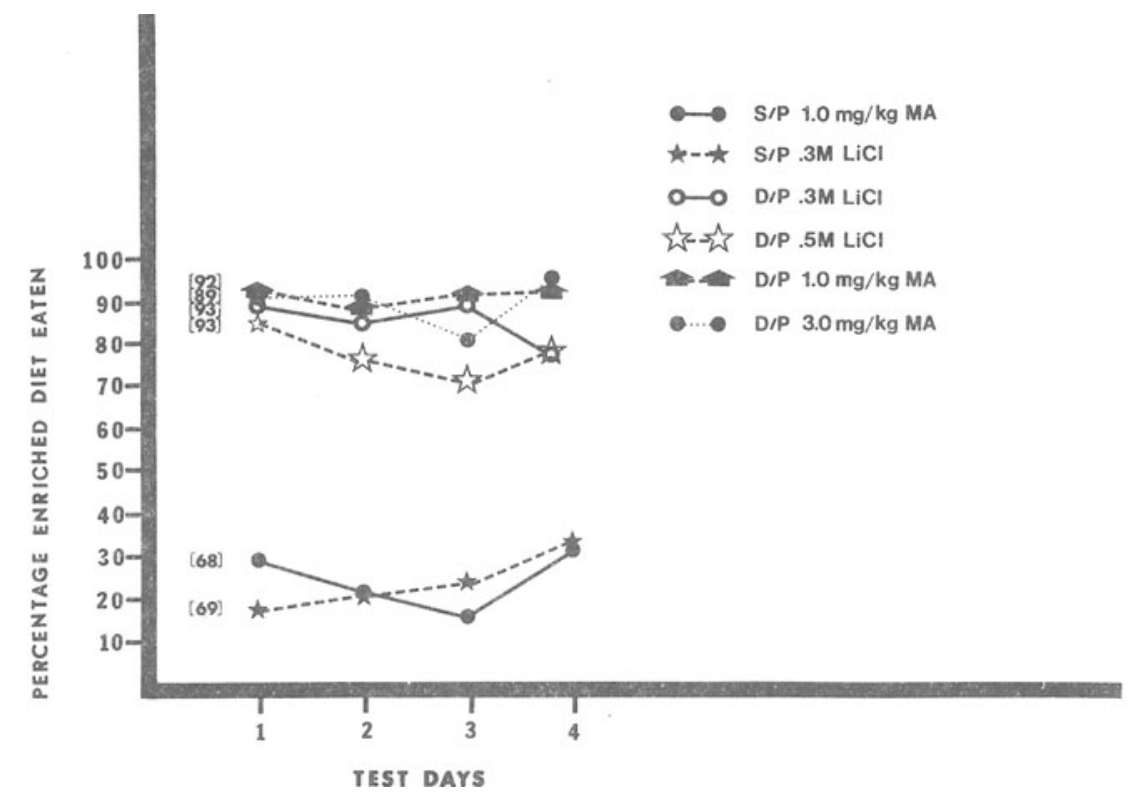

Figure 1. 
and Bean (1975), which demonstrated that pairing LiCl-induced toxicosis with a flavor previously paired with recovery from vitamin deficiency did not alter rats' preference for that flavor.

Of greater interest, however, is the finding that $D / P$ rats injected with either level of MA showed a resistance to toxicosis-induced aversion similar to $\mathrm{D} / \mathrm{P}$ rats injected with either level of $\mathrm{LiCl}$. S/P rats that were injected with MA, on the other hand, showed a marked aversion to the $\mathrm{CE}$ diet, as did S/P rats injected with $\mathrm{LiCl}$. Thus the present findings strongly suggest that pairing a flavor with recovery from vitamin deficiency prevents rats' forming aversions to that flavor when it is subsequently associated with unpleasant consequences, regardless of the agent used in the attempt to induce aversion.

\section{REFERENCES}

Buskist, W. F., Miller, H. L., Duncan, P., \& Fleming, D. E. Associative history determines strength of taste-aversion conditioning in thiamine-deficient rats. Physiology \& Behavior, 1980, 25, 989-992.
Buskist, W. F., Miller, H. L., Fleming, D. E., \& Sparenborg, S. P. Associatiye history, not familiarity, determines strength of taste-aversion conditioning in thiamine-deficient rats. Bulletin of the Psychonomic Society, 1981, 17, 104-106.

GAMzU, E. The multifaceted nature of taste-aversion-inducing agents: Is there a single common factor? In L. M. Barker, M. R. Best, \& M. Domjan (Eds.), Learning mechanisms in food selection. Waco, Tex: Baylor University Press, 1977.

LEBlanc, A. E., \& CAPPELL, H. Attenuation of punishing effects of morphine and amphetamine by chronic prior treatment. Journal of Comparative and Physiological Psychology, 1974, 87, 691-698.

Rodgers, W., \& Rozin, P. Novel food preference in thiaminedeficient rats. Journal of Comparative and Physiological Psychology, 1966, 61, 1-4.

Vogel, J. R., \& Clody, D. E. Habituation and conditioned food aversion. Psychonomic Science, 1972, 28, 275-276.

ZAHORIK, D. M. Associative and non-associative factors in learned food preferences. In L. M. Barker, M. R. Best, \& M. Domjan (Eds.), Learning mechanisms in food selection. Waco, Tex: Baylor University Press, 1977.

ZahORIK, D. M., \& BEAN, C. A. Resistance of "recovery" flavors to later association with illness. Bulletin of the Psychonomic Society, 1975, 6, 309-312.

(Received for publication April 16, 1981.) 